\title{
Immunohistochemical Study of Androgen Receptor Expression in Estrogen Receptor-Negative Invasive Breast Carcinoma and its Relation with Clinicopathologic Factors
}

\author{
Shereen E. Abdelaal ${ }^{1 *}$, Samia M. Gabal ${ }^{2}$, Amina A. Gamal el Din ${ }^{1}$, Hala N. Hosni ${ }^{2}$, Hafiza A. Sharaf ${ }^{1}$ \\ ${ }^{1}$ Department of Pathology, National Research Centre, Giza, Egypt; ${ }^{2}$ Department of Pathology, Faculty of Medicine, Cairo \\ University, Cairo, Egypt
}

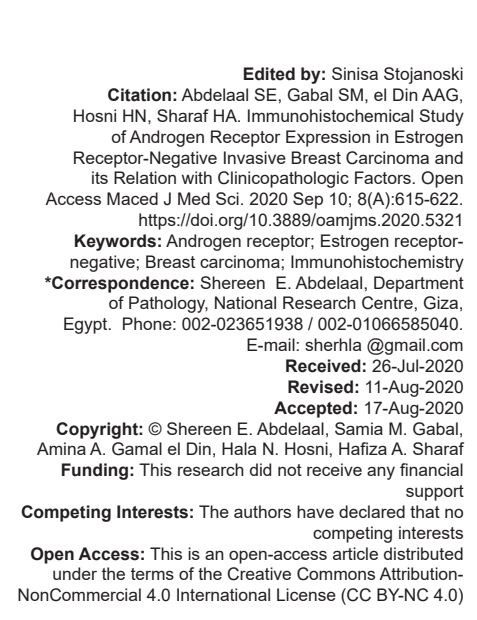

\section{Introduction}

Breast cancer is the most common cancer in females and a leading cause of death [1]. In Egypt, breast cancer proved to be the commonest cancer in females accounting for $32.04 \%$ of all malignant tumors [2]. Gene-DNA wise, breast cancer is subdivided into: Luminal A, luminal B, normal-like, basal-like, and human epidermal growth factor receptor-2 (HER-2) overexpression categories [3]. Another subtyping for breast cancer includes: One subtype expressing estrogen receptor (ER-positive) tumors and another subtype non-expressing (ER-negative) tumors [4]. ER-negative tumors accounted for $25-30 \%$ of breast carcinomas. Unfortunately, they have fewer strategies for therapy in comparison to ER-positive tumors [5]. ER-negative tumor group includes triple-negative tumors being negative for ER, progesterone receptor (PR) and HER2 and tumors which are positive for
HER-2. They are not subjected for antiestrogenic therapy and the triple-negative tumors lack any specific targeted therapy [6]. Thus, an ultimate goal for research in the field of breast cancer is to find more biomarkers as potential targets for therapy [7]. The androgen receptor (AR) is a newly emerge biomarker. About $70-80 \%$ of breast carcinomas show AR; which being a steroid hormone is highly similar to ER and $P R$, structure wise, and function wise. The role of ER/PR is wellestablished with respect to therapy and prognosis of breast carcinoma. However, the importance of detection of AR in breast carcinoma is still unclear [8]. Therefore, the aim of this study is to examine the immunohistochemical expression profiles of AR protein in ER-negative invasive breast carcinomas for the possible use of $A R$ as a target therapy and to assess the relationship between $A R$ expression and the clinicopathologic prognostic factors such as age, tumor size, tumor grade, tumor type, immunohistochemical type, lymph node status, and Ki67 expression (as a proliferation marker). 


\section{Materials and Methods}

In this retrospective cross-sectional study, a total of 60 paraffin blocks of ER-negative invasive breast carcinoma cases, with known receptor status (ER, PR, and Her2), were retrieved from the Pathology Department at Kasr El-Aini Hospitals, Cairo University. The clinicopathological parameters such as age, tumor size, tumor grade, tumor histological type, and lymph node status, were retrieved from the patient's pathology reports. The cases were anonymous as an ethical requirement. The Medical Research Ethics Committee of National Research Centre, Cairo, Egypt, approved the study (No. 12067).

Three sections of $4 \mu \mathrm{m}$ thickness were cut from each block; one section was stained with hematoxylin and eosin to establish the diagnosis. The tumors were histologically graded according to ElstonEllis modification of Scarff-Bloom-Richardson grading system [9]. The histological types were determined according to the fifth edition of the WHO classification of invasive breast carcinoma [10]. Tumor staging was based on TNM classification according to American Joint Committee on Cancer, $8^{\text {th }}$ edition [11]. The other two sections were mounted on positively charged glass slides for immunohistochemical staining by AR and Ki67.

Immunohistochemical staining for $A R$ was done using AR Rabbit Monoclonal Antibody (SP107, 200R-16, $1.0 \mathrm{ml}$, concentrate, 1: 50 dilution, Cell Marque, USA). Heat-induced epitope retrieval technique was used applying Cell Marque's Trilogy together with a pressure cooker permitting simultaneous deparaffinization, rehydration, and epitope retrieval. The used detection system was Econo Tek HRP AntiPolyvalent (DAB), Ready-to-Use (ScyTek Laboratories, U.S.A). Known prostatic carcinoma sections were used as a positive control. In the negative control, $1 \%$ bovine serum albumin was used in place of the primary antibody.

The primary Rabbit Polyclonal anti-Ki-67 Antibody (RB-9043-P; 1.0 ml, 1: 50 dilution, Thermo Fisher Scientific, Fremont, USA) was used for Ki67 immunohistochemical staining.

Semi-automated evaluation of $\mathrm{AR}$ and $\mathrm{Ki} 67$ was performed using the digital light microscope (Leica DM 3000, LED) of the Leica Qwin Image Analyzer system (V3,5,1-LEICA Imaging Systems Ltd, Cambridge, England,), at the Pathology Department in the National Research Centre.

In all cases, AR immunoreactivity was assessed as the percentage of positive cells. We considered nuclear immunopositivity of $\geq 1 \%$ of malignant cells as the cutoff point for positivity, according to the American Society of Clinical Oncology (ASCO) and the College of American Pathologists (CAP) guidelines and recommendations for immunohistochemical interpretation of hormone receptors in breast cancer [12].

Two scoring systems were used for AR expression scoring; $\mathrm{H}$-score method [7], and Allred Score system [13]. In H-Score system, the score was given as the percentage of the immunopositive nuclei (0-100\%) multiplied by a value corresponding to level of intensity ( 0 none, 1 weak, 2 moderate, and 3 strong). The score result ranged between 0 (no staining in the tumor) and 300 (diffuse strong staining of the tumor). In Allred score intensity and proportion score were applied. Intensity score was the one used in $\mathrm{H}$ score (0-3). The proportion score applied counted the percentage of the immunopositive nuclei; categorizing them into six subgroups $(0$, no staining; $1,<1 \% ; 2$, between $1 \%$ and $10 \% ; 3$, between $11 \%$ and $33 \%$; 4 , between $34 \%$ and $66 \%$; and 5 , between $67 \%$ and $100 \%$ of the cells staining). A total score was obtained by adding the proportion score and intensity score. The total score was graded on a scale from 0 to 8 , where Allred score of 0,2 indicated a negative result, while cutoff to positivity was three or more.

The immunohistochemical analysis of Ki67 was performed following recommendations from the International Ki67 in Breast Cancer Working Group. The entire section was scanned at low-power magnification $(\times 100)$ to determine areas with the highest numbers of positive nuclei (hot spots) within the tumor tissue. Only nuclear staining is considered positive. Staining intensity is not relevant. Ki67 proliferative index assessment was expressed as the percentage of ki67positive cells within the total number of malignant cells among five high-power fields $(\times 400)$.A percentage of $15 \%$ or more was considered to be a cutoff point [14].

\section{Statistics}

The collected data were coded, tabulated, and statistically analyzed using Statistical Package for the Social Sciences (SPSS) program, software version 18.0 .

Descriptive statistics were done for quantitative data; as minimum and maximum of the range as well as mean $\pm S D$ (standard deviation) for quantitative parametric data, and as median, $1^{\text {st }}$ and $3^{\text {rd }}$ inter-quartile range for quantitative non-parametric data. It was done for qualitative data as number and percentage. The analyses were done for quantitative variables using independent t-test in cases of two independent groups with parametric data. In qualitative data, analyses for independent variables were done using Chi-square test for differences between proportions and Fisher's exact test for variables with small expected numbers, while correlations were done using spearman test for numerical non-parametric and qualitative data.

The level of significance was taken at $p \leq 0.05$ is significant, otherwise is non-significant. 


\section{Results}

In the studied cases, the age ranged between 25 and 71 years with a mean age of 49.3 years \pm 12.7 . The studied cases consisted of 45 cases of invasive ductal carcinoma (Figure 1), eight cases of invasive lobular carcinoma (Figure 2), four cases of medullary carcinoma (Figure 3), one case of mucinous carcinoma

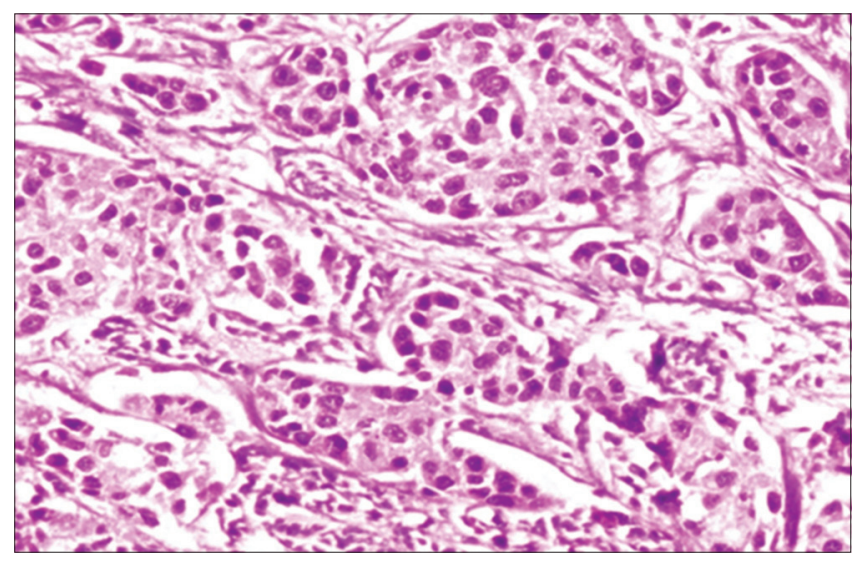

Figure 1: Invasive ductal carcinoma, showing sheets and clusters of malignant ductal epithelial cells with moderate anaplasia and pleomorphism, together with moderate attempts at ductal formation (Grade II), ( $H$ and E, ×400)

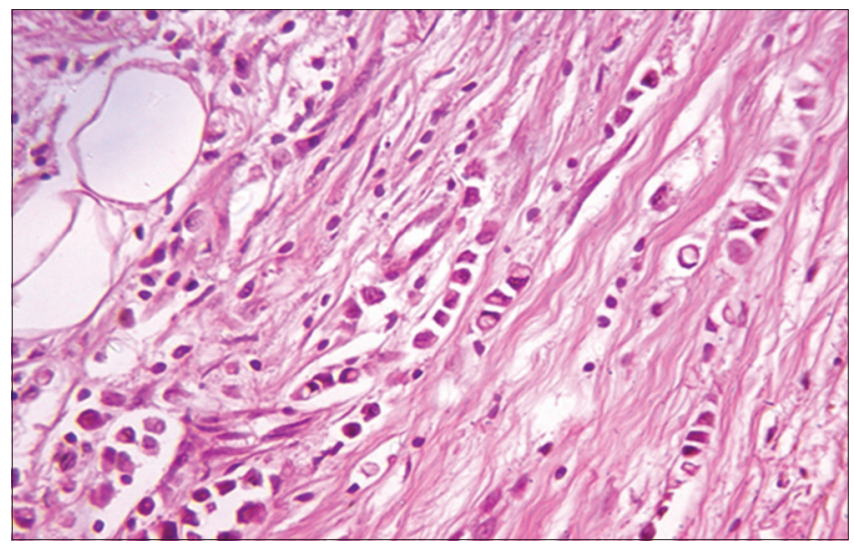

Figure 2: Invasive breast lobular carcinoma showing, small uniform tumor cells arranged in single file (Indian file) pattern ( $H$ and $E, \times 400$ )

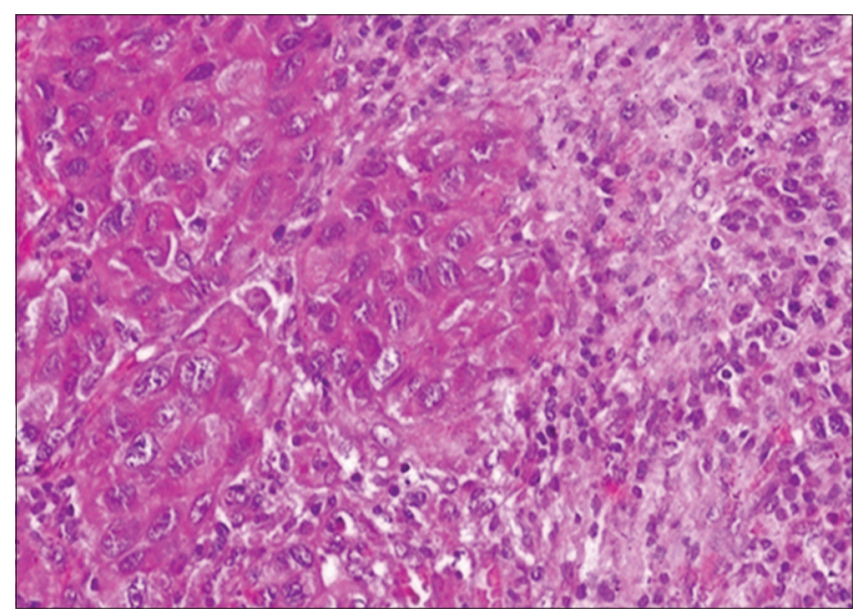

Figure 3: Breast medullary carcinoma, showing syncytial sheets of large tumor cells, highly pleomorphic with indistinct cell borders and prominent nucleoli. The surrounding stroma shows dense lymphoplasmacytic infiltrate ( $H$ and $E, \times 400)$
(Figure 4), one case of secretory carcinoma, and one case of tubular carcinoma. The cases were subdivided

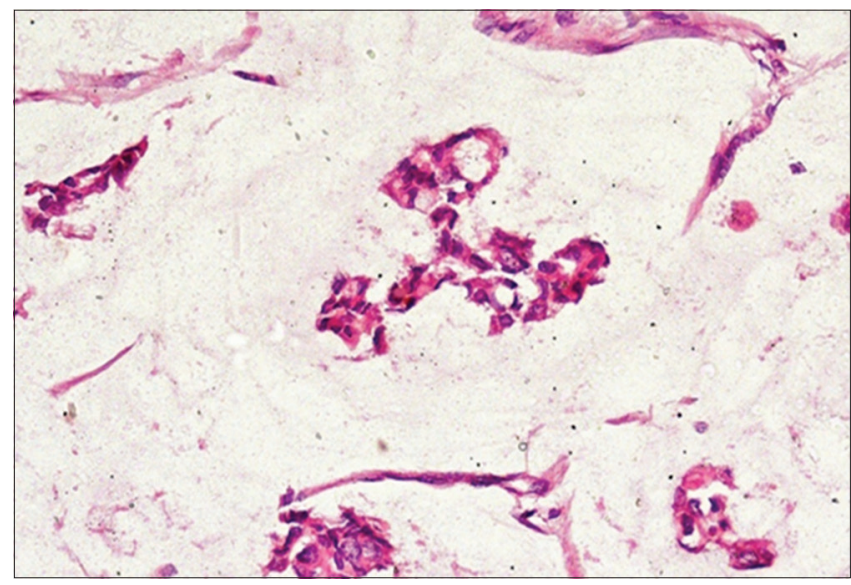

Figure 4: Breast mucinous carcinoma showing clusters of malignant epithelial cells floating within pools of extracellular mucin $(H$ and $E$, $\times 400)$

into two immunohistochemical types; HER-2 positive tumors type (ER-negative, PR-negative, and HER2positive) and the triple negative (TN) tumors type (ER-negative, PR-negative, and HER2-negative). The majority of the cases were Grade II (73.3\%), followed by Grade III (26.7\%). The distribution of histological types, immunohistochemical types, and tumor grade among the studied cases are represented in Table 1.

Table 1: Distribution of histological types, immunohistochemical types and tumour grade among the studied cases

\begin{tabular}{ll}
\hline Pathologic features & $\mathrm{n}=60, \mathrm{n}(\%)$ \\
\hline Histological types & \\
Ductal carcinoma & $45(75)$ \\
Lobular carcinoma & $8(13.3)$ \\
Medullary carcinoma & $4(6.7)$ \\
Mucinous carcinoma & $1(1.7)$ \\
Secretory carcinoma & $1(1.7)$ \\
Tubular carcinoma & $1(1.7)$ \\
Immunohistochemical types: & $23(38.3)$ \\
Triple negative & $37(61.7)$ \\
HER2 positive & \\
Tumour grade & $44(73.3)$ \\
Grade II & $16(26.7)$ \\
Grade III & \\
\hline
\end{tabular}

The tumor specimens consisted of 21 specimens of core biopsies and 39 specimens of mass biopsies (lumpectomy or modified radical mastectomy). The size distribution among the mass biopsies is shown in Table 2. In the studied cases, the lymph node statuses were known in modified radical mastectomy cases and unknown in lumpectomy and core biopsy cases. The lymph node status distribution among the studied cases is represented in Table 3.

AR positivity was detected in 33 cases $(55 \%)$ out of the sixty studied cases. Twenty-eight cases

Table 2: Tumor specimens and mass size distribution among the studied cases

\begin{tabular}{ll}
\hline Tumor specimens & $\mathrm{n}=60, \mathrm{n}(\%)$ \\
\hline Mass & $39(65.0)$ \\
Core biopsy (pTX) & $21(35.5)$ \\
\hline Mass size & $\mathrm{n}=39, \mathrm{n}(\%)$ \\
\hline pT1 & $5(12.8)$ \\
pT2 & $18(46.2)$ \\
pT3 & $14(35.9)$ \\
pT4 & $2(5.1)$ \\
\hline
\end{tabular}


Table 3: Lymph node status distribution among the studied cases

\begin{tabular}{ll}
\hline Status & $\mathrm{n}=60, \mathrm{n}(\%)$ \\
\hline Known & $29(48.3)$ \\
Unknown (pNX) & $31(51.7)$ \\
\hline Lymph node status distribution $\mathrm{n}=29, \mathrm{n}(\%)$ & \\
\hline $\mathrm{pN0}$ & $5(27.6)$ \\
$\mathrm{pN} 1$ & $18(34.5)$ \\
$\mathrm{pN} 2$ & $14(20.7)$ \\
$\mathrm{pN3}$ & $2(17.2)$ \\
\hline
\end{tabular}

( $46.7 \%)$ had $\geq 10 \%$ of tumor cell nuclei staining positive for AR, five cases $(8.3 \%)$ had $<10 \%$ of tumor cell nuclei staining positive for $A R$, and 27 cases $(45 \%)$ were $A R$ negative $(<1 \%$ positivity). The characteristics of AR positive cases (Intensity, AR \%, H-score, and Allred score) are shown in details in Table 4.

Table 4: Characteristics of AR positive cases

\begin{tabular}{lll}
\hline Intensity & $\mathrm{n}=33$ & $\%$ \\
\hline Mild & 10.0 & 30.3 \\
Moderate & 4.0 & 12.1 \\
Strong & 19.0 & 57.6 \\
\hline Degree of positivity & Median (IQR) & Range \\
\hline AR \% & $41.0(19.0-9.0)$ & $2.0-95.0$ \\
H-score & $117.0(19.0-207.0)$ & $3.0-285.0$ \\
Allred score & $7.0(4.5-8.0)$ & $3.0-8.0$ \\
\hline IQR: Interquartile range. & &
\end{tabular}

The mean age of AR positive cases was $51 \pm 11.7$ years; while the mean age of $A R$ negative cases was $47.1 \pm$ 13.7. AR expression was non-significantly higher in older age; higher AR expression $(57.6 \%$ of AR positive cases) was noted in patients aged above 50 years (Table 5 ).

Table 5: Comparison between AR positive and negative cases regarding age

\begin{tabular}{|c|c|c|c|}
\hline Types & AR positive $(n=33)$ & AR negative $(n=27)$ & $\mathrm{p}$-value \\
\hline Age (years) & $51.1 \pm 11.7$ & $47.1 \pm 13.7$ & $\# 0.230$ \\
\hline \multicolumn{4}{|l|}{ Age } \\
\hline$\leq 50$ (years) & $14(42.4 \%)$ & $14(51.9 \%)$ & ${ }^{\wedge} 0.708$ \\
\hline$>50$ (years) & $19(57.6 \%)$ & $13(48.1 \%)$ & \\
\hline
\end{tabular}

The AR expression in different histological types was variable (Figures $5-8$ ), $55.6 \%$ of invasive ductal carcinomas and $75 \%$ of invasive lobular carcinomas were positive for AR, while all medullary carcinomas cases were negative for AR. AR expression was higher within Grade II tumor cases (61.4\%). AR was expressed in $51.4 \%$ of

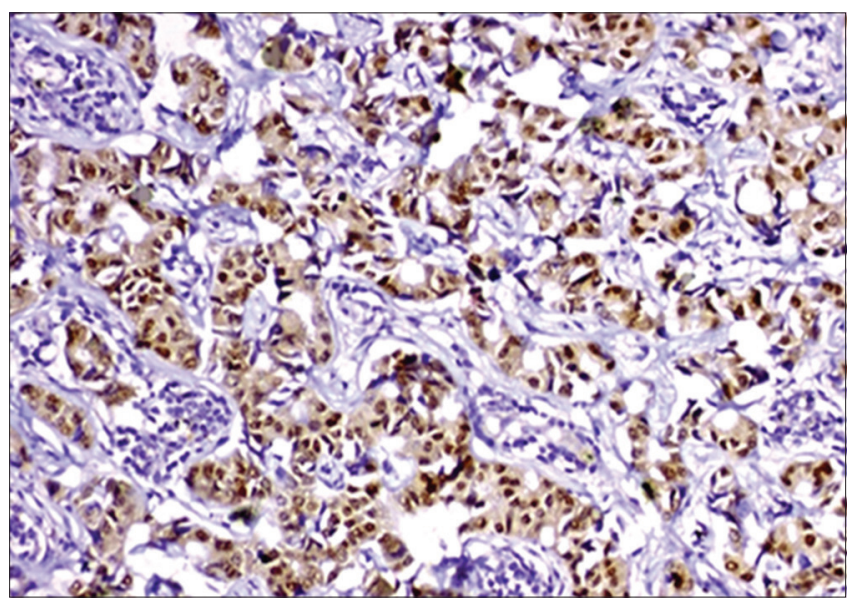

Figure 5: Invasive ductal carcinoma, showing strong AR staining and high percentage of expression (92\%). H score $=276$ and Allred score $=8$ (Immunoperoxidase, $\times 200)$

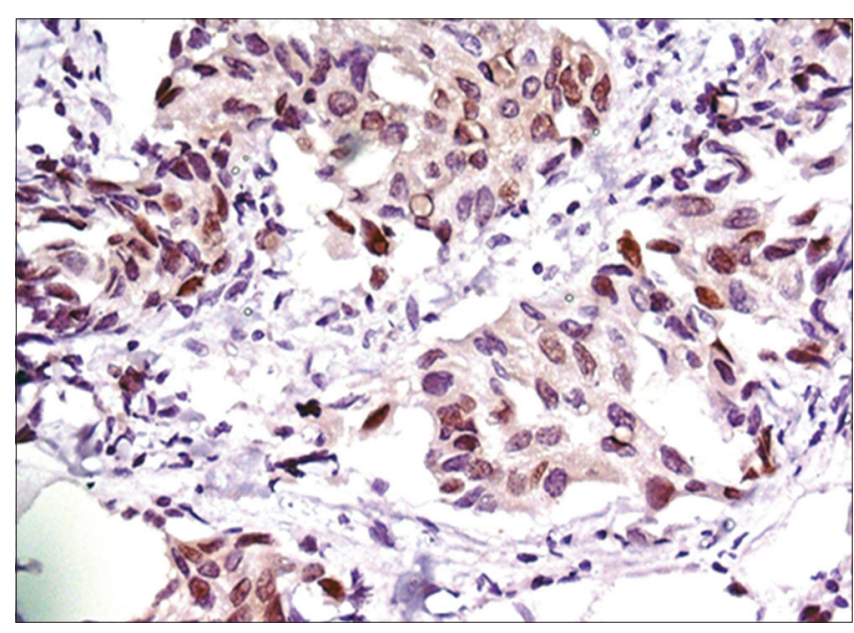

Figure 6: Invasive ductal carcinoma, showing strong AR staining and high percentage of expression (68\%). $\mathrm{H}$ score $=204$ and Allred score $=8$ (Immunoperoxidase, $\times 400$ )

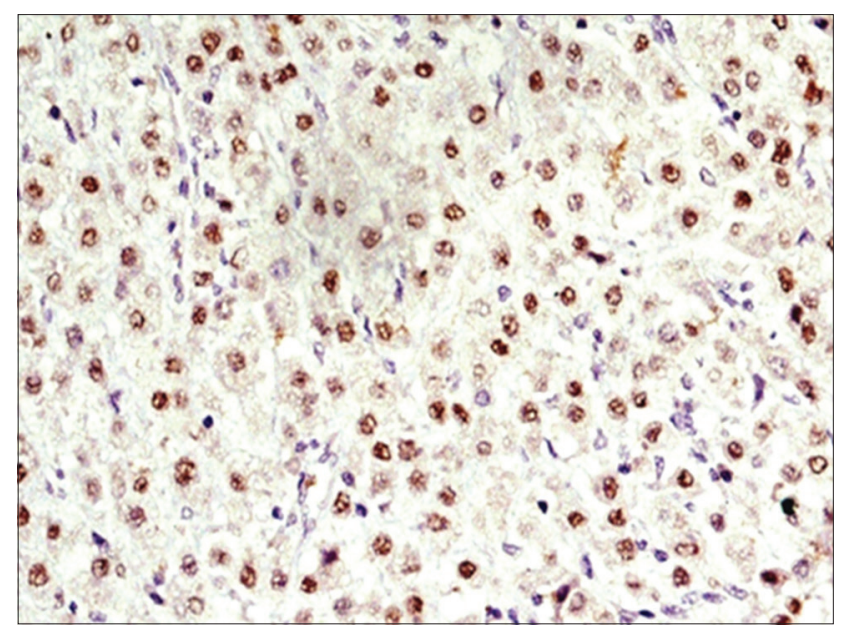

Figure 7: Breast lobular carcinoma, showing strong AR staining and high percentage of expression (70\%). $H$ score $=210$ and Allred score $=8$ (Immunoperoxidase, $\times 200)$

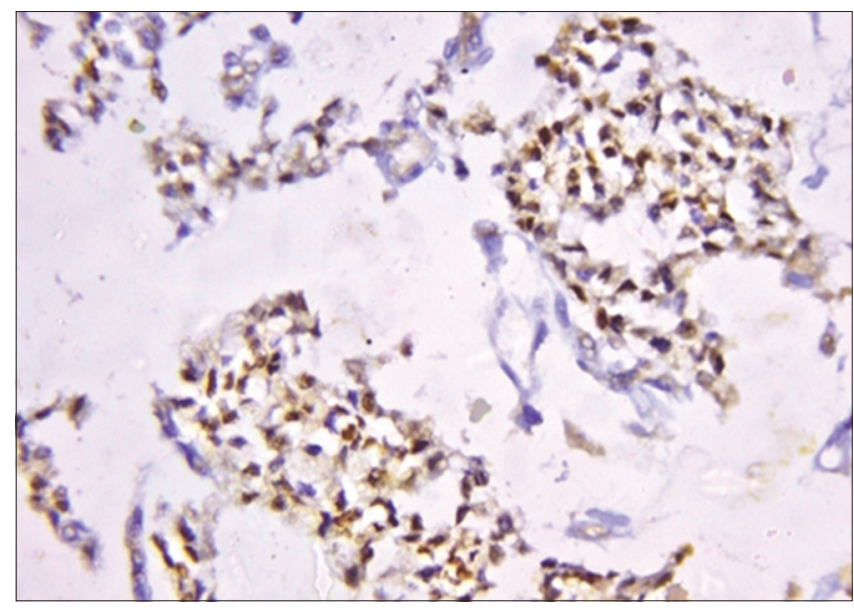

Figure 8: Mucinous carcinoma breast, showing strong AR staining and high percentage of expression (90\%). $H$ score $=270$ and Allred score $=8$ (Immunoperoxidase, $\times 400$ )

HER2-positive tumors and in $60.9 \%$ among TN tumors. In spite of a high percentage of AR expression in TN tumor cases, the $p$ value was not statistically significant. There was no significant difference between AR positive and AR 
negative cases regarding Ki67 expression. The relationship between AR expression and the histopathological parameters is shown in details in (Table 6).

Table 6: Comparison between AR positive and negative cases regarding histopathological parameters

\begin{tabular}{|c|c|c|c|c|}
\hline $\begin{array}{l}\text { Histopathological } \\
\text { parameters }\end{array}$ & $\begin{array}{l}\text { Total } \\
\text { number (n) }\end{array}$ & $\begin{array}{l}\text { AR positive cases: } \\
\mathrm{n}(\%)\end{array}$ & $\begin{array}{l}\text { AR negative } \\
\text { cases: } \mathrm{n}(\%)\end{array}$ & $p$-value \\
\hline \multicolumn{5}{|l|}{ Tumour grade } \\
\hline Grade II & 44 & $27(61.4)$ & $17(38.6)$ & \multirow[t]{2}{*}{${ }^{\wedge} 0.100$} \\
\hline Grade III & 16 & $6(37.5)$ & $10(62.5)$ & \\
\hline \multicolumn{5}{|l|}{ Tumour size } \\
\hline PT1 & 5 & $2(40)$ & $3(60)$ & \multirow[t]{4}{*}{$1.000 \#$} \\
\hline PT2 & 18 & $8(44.4)$ & $10(55.6)$ & \\
\hline PT3 & 14 & $7(50)$ & $7(50)$ & \\
\hline PT4 & 2 & $1(50)$ & $1(50)$ & \\
\hline \multicolumn{5}{|l|}{ Lymph node status } \\
\hline PNO & 8 & $5(62.5)$ & $3(37.5)$ & \multirow[t]{4}{*}{$0.846 \#$} \\
\hline PN1 & 10 & $4(40)$ & $6(60)$ & \\
\hline PN2 & 6 & $3(50)$ & $3(50)$ & \\
\hline PN3 & 5 & $2(40)$ & $3(60)$ & \\
\hline \multicolumn{5}{|l|}{$\begin{array}{l}\text { Tumour histological } \\
\text { types }\end{array}$} \\
\hline Ductal & 45 & $25(55.6)$ & $20(44.4)$ & \multirow[t]{4}{*}{ \#0.083 } \\
\hline Lobular & 8 & $6(75)$ & $2(25)$ & \\
\hline Medullary & 4 & $0(0.0)$ & $4(100)$ & \\
\hline Other special types* & 3 & $\begin{array}{l}2 \text { (66.7), } \\
\text { (mucinous, tubular) }\end{array}$ & $\begin{array}{l}1 \text { (33.3), } \\
\text { (secretory) }\end{array}$ & \\
\hline \multicolumn{5}{|c|}{ Immunohistochemical types } \\
\hline HER2 positive & 37 & $19(51.4)$ & $18(48.6)$ & \multirow[t]{2}{*}{${ }^{\wedge} 0.471$} \\
\hline TN & 23 & $14(60.9)$ & $9(39.1)$ & \\
\hline \multicolumn{5}{|l|}{ Ki67 expression } \\
\hline$K i 67 \geq 15 \%$ & 42 & $23(54.8)$ & $19(45.2)$ & \multirow[t]{2}{*}{${ }^{\wedge} 0.955$} \\
\hline Ki67 $<15 \%$ & 18 & $10(55.6)$ & $8(44.4)$ & \\
\hline
\end{tabular}

Spearman correlation was done between the degree of AR expression (AR \%, AR intensity, H-score, and Allred score) and variables such as age, HER2 expression, tumor size, lymph node status, and Ki67 expression (Table 7). There was significant positive correlation between the degree of AR expression (AR\%, AR intensity, and $\mathrm{H}$-score) and age (Figure 9). There was non-significant negative correlation between $\mathrm{Ki} 67 \%$ and the degree of $\mathrm{AR}$ expression (AR\%, AR intensity, $\mathrm{H}$-score, and Allred score) (Figure 10).

Table 7: Correlation between degree of AR positivity expression and other variables

\begin{tabular}{llllll}
\hline Variable & Measure & AR $\%$ & AR intensity & H-score & Allred score \\
\hline Age & $\mathrm{r}$ & 0.341 & 0.463 & 0.372 & 0.299 \\
& $\mathrm{p}$ & $0.050^{*}$ & $0.007^{*}$ & $0.033^{*}$ & 0.091 \\
HER2 expression & $\mathrm{N}$ & 33 & 33 & 33 & 33 \\
& $\mathrm{r}$ & 0.242 & 0.045 & 0.178 & 0.085 \\
Tumor size & $\mathrm{p}$ & 0.175 & 0.804 & 0.322 & 0.637 \\
& $\mathrm{~N}$ & 33 & 33 & 33 & 33 \\
LN status & $\mathrm{r}$ & -0.083 & -0.060 & -0.083 & 0.004 \\
& $\mathrm{p}$ & 0.742 & 0.812 & 0.742 & 0.987 \\
Ki67\% expression & $\mathrm{N}$ & 18 & 18 & 18 & 18 \\
& $\mathrm{r}$ & 0.403 & 0.312 & 0.385 & 0.292 \\
& $\mathrm{p}$ & 0.153 & 0.277 & 0.174 & 0.311 \\
& $\mathrm{~N}$ & 14 & 14 & 14 & 14 \\
& $\mathrm{r}$ & -0.209 & -0.331 & -0.208 & -0.140 \\
& $\mathrm{p}$ & 0.244 & 0.060 & 0.245 & 0.436 \\
Correlations are within AR positive cases r: Spearman correlation, ${ }^{\text {*Significant. }}$ &
\end{tabular}

\section{Discussion}

In the current study, AR positivity was detected in 33 cases $(55 \%)$ out of the sixty studied cases with a median of $41 \%$ of AR nuclear immunoreactivity (range 2-95\%). Twenty-eight cases (46.7\%) had $\geq 10 \%$

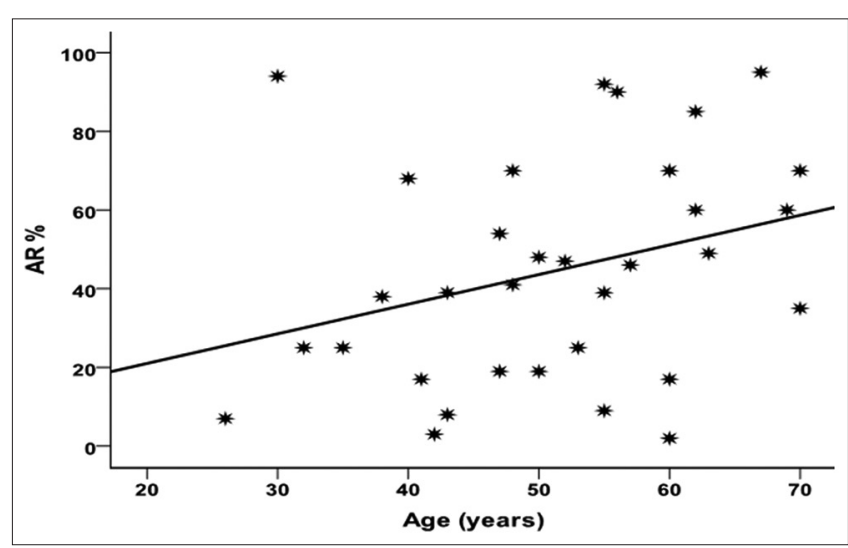

Figure 9:Correlation between degree of AR expression and age

of tumor cell nuclei staining positive for AR, and five cases $(8.3 \%)$ had $<10 \%$ of tumor cell nuclei staining positive for AR. Twenty-seven cases (45\%) were AR negative $(<1 \%$ positivity). These results were nearly similar to the results of Micello et al. [15]; who observed AR positivity in one hundred and 28 cases (56.6\%), having $59 \%$ as average AR immunostaining within nuclei (range $10-100 \%$ ). Among those, $48.8 \%$ of cases showed $>10 \%$ positive cells, while $7.8 \%$ cases showed $<10 \%$ cells with positive staining within nuclei, and $43.4 \%$ of the cases were negative for AR negative.

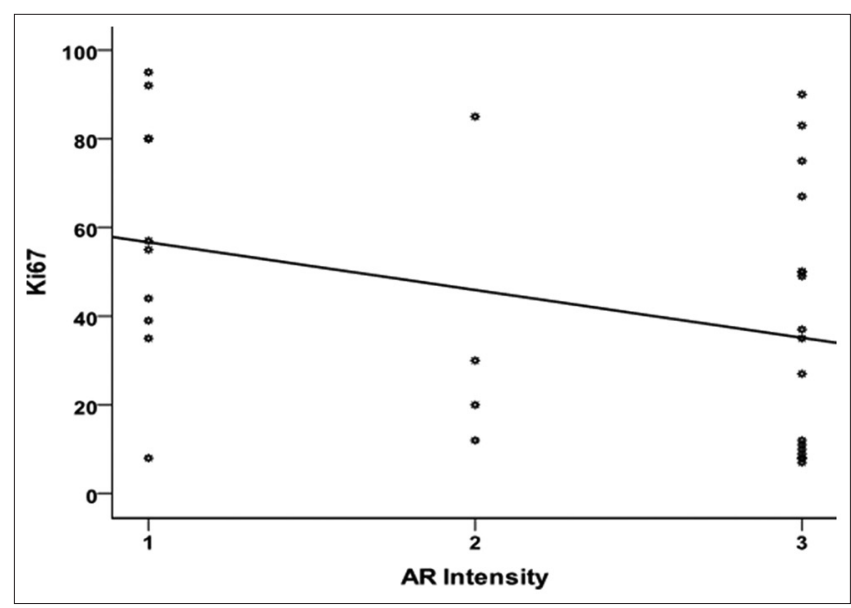

Figure 10: Correlation between Ki67 expression and AR intensity

Our results were also nearly in agreement with the study of Park et al. [16], who mentioned that the AR positive immunoreactivity was observed in $50 \%$ (65 of 130) of cases negative for ER. Furthermore, in the study of $\mathrm{Hu}$ et al. [17], the positivity for AR was noticed in $42.9 \%$ among 303 cases of women with tumors negative for ER, and it was $44 \%$ in the study of Collins et al. [18]. The study of Yu et al. [19] showed that $A R$ immunohistochemical staining was found in $53.2 \%(58 / 109)$ of cases negative for ER, while Qi et al. [20] showed that AR immunoreactivity was found in $65 \%$ (248 out of 383 cases) of tumors negative for ER.

The cutoff value for positivity for hormone receptor was considered as staining of $10 \%$ or more nuclei in the tumor. To allow largest number of 
patients to benefit from therapy antagonizing the hormone estrogen, the ASCO mentioned the cutoff value for positivity for hormone receptor to be $1 \%$ of stained cells instead of $10 \%$ [21]. We used $1 \%$ as the minimum staining required for AR positivity; similar to the most recent ASCO/CAP guidelines for evaluation of hormone receptors and similar to the most recent studies of [21], [22], [23], [12]. Meanwhile, other studies had used the $10 \%$ as the minimum requirement for a positive interpretation [15], [19]. Tumors having 1-9\% IHC immunoreactivity showed controversies regarding their category as being considered immunopositive or immunonegative; and subsequently as to whether or not to use endocrine therapy [13]. According to the most recent ASCO/CAP guidelines update for evaluation of hormone receptors, these category should be reported as low positive [12]. Hence, in this study, we subdivided the positive cases into two categories, one had $<10 \%$ positivity and the other had $10 \%$ or more.

In our study, raising the minimum threshold for $A R$ immunopositivity from $\geq 1 \%$ to $\geq 10 \%$ could result in losing $8.3 \%$ of all cases positive for $A R$, and $8.7 \%$ of TN breast carcinoma (TNBC) cases positive for AR. In Safarpour et al. [24] study, elevating the minimum threshold for $A R$ immunopositivity from $\geq 1 \%$ to $\geq 10 \%$ would result in losing $4.6 \%$ of all cases positive for AR, and $22 \%$ of TNBC cases positive for AR. Subsequently, this group of cases would lose their chance for benefiting from therapy targeting hormone in the future.

For scoring of AR positive cases, we used two scoring systems. The first one was the $\mathrm{H}$-score with a median $=117$, and a score range of 3-285. The second one was the Allred score with a median $=7$, and a range of 3-8. Niemeier et al. [7] also used $\mathrm{H}$-score for scoring of AR immunohistochemical expression, having a median score $=150$, and a score range $=15-300$. However, Yu et al. [19] assessed AR expression using Allred score.

Cohen et al. [25] mentioned that the H-score details the percentage of cells showing none, weak, moderate, or strong staining; thus giving a wide dynamic range (0-300). On the other hand, the Allred score is obtained from summation of scores of proportion and intensity, thus giving a limited dynamic range (0-8). Hence, theoretically speaking, $\mathrm{H}$-score can provide clinicians with more information regarding prognosis. That is why some institutes prefer to use $\mathrm{H}$ Score. However, Brouckaert et al. [13] mentioned that for the time being, Allred score is the most established one and that a good cutoff to predict benefit from treatment targeting hormones is an Allred score of $\geq 3$.

In the current study, AR positivity was seen in the two ER-negative immunohistochemical types (according to expression of Her2). In HER2 positive type, AR positivity was detected in $51.4 \%$ (19 cases out of 37). In TN type, AR positivity was detected in $60.9 \%$ (14 cases out of 23 ). This was consistent with the results of Collins et al. [18], in which AR immunopositivity was detected in $58.7 \%$ of invasive carcinomas of the breast; positive for Her2. It was also in agreement with the study of Qi et al. [20], where AR positivity was observed in $55 \%$ of TNBCs. However, this was in contrast to the study of Niemeier et al. [7], in which AR immunopositivity was seen in $10 \%$ (3/30) of the triple-negative breast carcinomas. These variable percentages of AR immunopositivity in different studies among TNBCs may be attributed to the heterogeneity of the TN category; being molecularly classified into seven subtypes among which is the luminal AR (LAR) subtype (ER-, PR-, and $A R+$ ) showing highest $A R$ immunohistochemical expression and the other TN tumor subtypes (non-LAR) which may express AR but at a low immunohistochemical expression.

In this study, the frequency of $A R$ immunohistochemical expression varied according to histologic type of invasive breast carcinoma. AR expression was seen in $55.6 \%$ of invasive ductal carcinomas (NST) and $75 \%$ of invasive lobular carcinomas. The cases of both mucinous carcinomas and tubular carcinomas were positive for AR. Medullary and secretory carcinomas were negative for AR. This was similar to the study of Micello et al. [15], which showed $56.6 \%$ of AR positivity in invasive duct carcinomas negative for ER. This also agreed with the study of Collins et al. [18], in which AR expression was seen in the majority of tumor histopathologic types negative for ER as follows: $71.0 \%$ of duct carcinoma cases, $96.3 \%$ of lobular carcinoma cases, $80.5 \%$ of mucinous carcinoma cases, and $100 \%$ of tubular carcinoma cases. Similarly, the previous study showed that AR expression was seen in $73.6 \%$ of invasive duct carcinoma cases, $83.3 \%$ of invasive lobular carcinoma cases, $41.7 \%$ of mucinous carcinoma cases, $25 \%$ of medullary carcinoma cases, and $100 \%$ of tubular carcinoma cases. This was nearly consistent with our result, except for differences in medullary and mucinous carcinomas. This difference may be due to the different number of cases of each type included in each study [16].

In our study, age was non-significantly higher in cases positive for AR (mean, 51 years) than cases negative for AR (mean, 47 years). In AR positive cases, patients older than 50 years represented $57.6 \%$ while patients younger than 50 years represented $42.4 \%$. However, there was no significant difference by Chisquare test $(p=0.708)$. On the other hand, Spearman correlation showed significant positive correlations between the degree of $A R$ immunohistochemical expression (AR \% $(r=0.341, p=0.050)$, AR intensity $(r=0.463, p=0.007)$, and $\mathrm{H}$-score $(r=0.372, p=0.033)$ and age. This was nearly similar to the result of Pistelli et al. [26], where AR positive cases with age higher than 50 years accounted for $60 \%$ while patients younger than 50 years accounted for $40 \%$ of AR immunopositive cases; however, there was no significant difference $(p=0.9)$. This also was in agreement with McGhan et al. [27], where AR immunohistochemical expression was associated with older age of the patients as 
compared to tumors that were negative for AR expression. On the other hand, in Park et al. [16] study, there were no significant differences between AR immunohistochemical expression and age at the time of diagnosis. This contradiction may be due to the difference in the cutoff values of age used, as they used 35 years as a cutoff value for age grouping, while we used 50 years as a cutoff value.

Our results demonstrated a negative correlation between Ki67\% and the degree of AR expression (AR \% $(r=-0.209 ; p=0.244), A R$ intensity $(r=-0.331$; $p=0.060), H$-score $(r=-208 ; p=0.245)$, and Allred score $(r=-0.140 ; p=0.436)$, but it was non-significant. This was nearly consistent with the results of Sutton et al. [22], where the AR expression levels showed a negative correlation with Ki67 expression in the AR-positive tumors, and it was significant $(r=-0.55 ; p=0.0006)$. They supposed that the negative correlation may be related to the anti-proliferative effect of $A R$ stimulation and these findings further support the idea that high $A R$ levels may be associated with a better prognosis in some previous studies. This was also consistent with the results of Pistelli et al. [26], where positive AR immunostaining was inversely correlated with a higher Ki67.

In the current study, there was no significant difference between AR positive and AR negative cases regarding tumor size, tumor grade, HER-2 status, and lymph node status. These results were similar to the results that were mentioned by $\mathrm{Yu}$ et al. [19] who showed that AR immunohistochemical expression had no relation to the parameters, such as tumor size, lymph node status, histological grade, and HER-2 status. On the contrary Park et al. [16] mentioned that, AR showed significant immunohistochemical expression in patients with smaller tumor size $(p=0.035)$ and lower histologic grade $(p<0.001)$; the difference may be attributed to the larger number of cases used by them; giving more chance to reveal such clinicopathologic association.

We may conclude that $A R$ is frequently expressed in estrogen-negative invasive breast carcinoma (55\% positivity); especially in older age. AR is variably expressed in different histologic types of breast cancer, except in medullary and secretory carcinomas. $A R$ is expressed in a large number of triple-negative breast cancers $(60.9 \%)$ which indicates that AR could be a new target for therapy in this difficult to treat entity. AR positive breast carcinoma is more commonly noticed in older patients as the degree of AR expression has a significant positive correlation with higher age. There was a non-significant negative correlation between $\mathrm{Ki} 67 \%$ and the degree of AR expression. There is no significant difference between AR positive and $A R$ negative cases regarding tumor grade, tumor size, tumor immunohistochemical type, and lymph node status.

One important possible implication of this study is the future use of AR-related targeted therapy for breast cancer, especially for ER-negative/AR-positive tumors. We recommend further research work on AR in the special histological types of ER-negative breast carcinoma and in the TN group; using larger sample size. This may give more chance to investigate whether those tumors can be amenable to future AR target therapy.

\section{Acknowledgments}

The authors thank Prof. Dr. Marcell N. Boulos, for her kind supervision and valuable help.

\section{References}

1. Christopoulos PF, Vlachogiannis NI, Vogkou CT, Koutsilieris M The role of the androgen receptor signaling in breast malignancies. Anticancer Res. 2017;37(12):6533-40

PMid:29187427

2. Ibrahim AS, Khaled HM, Mikhail NN, Baraka H, Kamel H. Cancer incidence in Egypt: Results of the national populationbased cancer registry program. J Cancer Epidemiol. 2014;2014:e437971. https://doi.org/10.1155/2014/437971

3. Zhang L, Fang C, Xu X, Li A, Cai Q, Long X. Androgen receptor EGFR, and BRCA1 as biomarkers in triple-negative breast cancer: A meta-analysis. Biomed Res Int. 2015;2015:357485. https://doi.org/10.1155/2015/357485

PMid:25695063

4. Munirah MA, Siti-Aishah MA, Reena MZ, Sharifah NA, Rohaizak M, Norlia A, et al. Identification of different subtypes of breast cancer using tissue microarray. Rom J Morphol Embryol. 2011;52(2):669-77.

PMid:21655659

5. Ni M, Chen $\mathrm{Y}$, Lim E, Wimberly $\mathrm{H}$, Bailey ST, Imai $\mathrm{Y}$, et al. Targeting androgen receptor in estrogen receptor-negative breast cancer. Cancer Cell. 2011;20(1):119-31. https://doi. org/10.1016/j.ccr.2011.05.026

PMid:21741601

6. Garay JP, Park BH. Androgen receptor as a targeted therapy for breast cancer. Am J Cancer Res. 2012;2(4):434-45.

PMid:22860233

7. Niemeier LA, Dabbs DJ, Beriwal S, Striebel JM, Bhargava R. Androgen receptor in breast cancer: expression in estrogen receptor-positive tumors and in estrogen receptornegative tumors with apocrine differentiation. Mod Pathol. 2010;23(2):205-12. https://doi.org/10.1038/modpathol.2009.159 PMid:19898421

8. Vellaisamy G, Tirumalae R, Inchara YK. Expression of androgen receptor in primary breast carcinoma and its relation with clinicopathologic features, estrogen, progesterone, and her-2 receptor status. J Cancer Res Ther. 2019;15(5):989-93. https:// doi.org/10.4103/jcrt.jcrt_572_17

PMid:31603099

9. Damjanov I, Fan F. Cancer Grading Manual. $2^{\text {nd }}$ ed. Berlin: Springer-Verlag; 2013.

10. World Health Organization Classification of Tumours Editorial 
Board. Who Classification of Tumours: Breast Tumours. $5^{\text {th }}$ ed. Lyon, France: International Agency for Research on Cancer; 2019. p. 82-159.

11. Amin MB, Edge $S$, Greene F, Byrd DR, Brookland RK Washington MK, et al. AJCC Cancer Staging Manual. $8^{\text {th }}$ ed. New York: Springer International Publishing; 2017.

12. Allison KH, Hammond ME, Dowsett M, McKernin SE, Carey LA, Fitzgibbons $\mathrm{PL}$, et al. Estrogen and progesterone receptor testing in breast cancer: ASCO/CAP guideline update. J Clin Oncol. 2020;38(12):1346-66. https://doi.org/10.1200/ jco.19.02309

13. Brouckaert O, Paridaens R, Floris G, Rakha E, Osborne K, Neven P. A critical review why assessment of steroid hormone receptors in breast cancer should be quantitative. Ann Oncol. 2013;24(1):47-53. https://doi.org/10.1093/annonc/mds238 PMid:22847811

14. Dowsett M, Nielsen TO, A'Hern R, Bartlett J, Coombes RC Cuzick J, et al. Assessment of Ki67 in breast cancer: Recommendations from the international Ki67 in breast cancer working group. J Natl Cancer Inst. 2011;103(22):1656-64. https://doi.org/10.1093/jnci/djr393 PMid:21960707

15. Micello D, Marando A, Sahnane N, Riva C, Capella C, Sessa F. Androgen receptor is frequently expressed in HER2-positive, ER/ PR-negative breast cancers. Virchows Arch. 2010;457(4):46776. https://doi.org/10.1093/jnci/djr393 PMid:20809337

16. Park S, Koo J, Park HS, Kim JH, Choi SY, Lee JH, et al. Expression of androgen receptors in primary breast cancer. Ann Oncol. 2010;21(3):488-92. PMid:19887463

17. Hu R, Dawood S, Holmes MD, Collins LC, Schnitt SJ, Cole K, et al. Androgen receptor expression and breast cancer survival in postmenopausal women. Clin Cancer Res. 2011;17(7):186774. https://doi.org/10.1093/jnci/djr393 PMid:21325075

18. Collins LC, Cole KS, Marotti JD, Hu R, Schnitt SJ, Tamimi RM Androgen receptor expression in breast cancer in relation to molecular phenotype: Results from the nurses' health study. Mod Pathol. 2011;24(7):924-31. https://doi.org/10.1038/ modpathol.2011.54 PMid:21552212

19. Yu Q, Niu Y, Liu N, Zhang JZ, Liu TJ, Zhang RJ, et al. Expression of androgen receptor in breast cancer and its significance as a prognostic factor. Ann Oncol. 2011;22:1288-94. https://doi. org/10.1093/annonc/mdq586

PMid:21109569

20. Qi JP, Yang YL, Zhu H, Wang J, Jia Y, Liu N, et al. Expression of the androgen receptor and its correlation with molecular subtypes in 980 chinese breast cancer patients. Breast Cancer (Auckl). 2012;6:1-8. https://doi.org/10.4137/bcbcr.s8323 PMid:22259247

21. Prabhu JS, Korlimarla A, Desai $K$, Alexander A, Raghavan $R$, Anupama C, et al. A majority of low (1-10\%) ER positive breast cancers behave like hormone receptor negative tumors. J Cancer. 2014;5(2):156-65. https://doi.org/10.7150/jca.7668 PMid:24563670

22. Sutton LM, Cao D, Sarode V, Molberg KH, Torgbe K, Haley B, et al. Decreased androgen receptor expression is associated with distant metastases in patients with androgen receptorexpressing triple-negative breast carcinoma. Am J Clin Pathol. 2012;138(4):511-6. https://doi.org/10.1309/ajcp8avf8fdptzlh PMid:23010705

23. Mrklić I, Pogorelić Z, Capkun V, Tomić S. Expression of androgen receptors in triple negative breast carcinomas. Acta Histochem. 2013;115(4):344-8. https://doi.org/10.1016/j.acthis.2012.09.006 PMid:23031358

24. Safarpour D, Pakneshan S, Tavassoli FA. Androgen receptor (AR) expression in 400 breast carcinomas: Is routine AR assessment justified? Am J Cancer Res. 2014;4(4):353-68. PMid:25057438

25. Cohen DA, Dabbs DJ, Cooper KL, Amin M, Jones TE, Jones MW, et al. Interobserver agreement among pathologists for semiquantitative hormone receptor scoring in breast carcinoma. Am J Clin Pathol. 2012;138(6):796-802. https://doi. org/10.1309/ajcp6dkrnd5ckvdd

PMid:23161712

26. Pistelli $M$, Caramanti $M$, Biscotti $T$, Santinelli A, Pagliacci $A$, De Lisa $\mathrm{M}$, et al. Androgen receptor expression in early triplenegative breast cancer: Clinical significance and prognostic associations. Cancers (Basel). 2014;6(3):1351-62. https://doi. org/10.3390/cancers6031351

PMid:24978437

27. McGhan LJ, McCullough AE, Protheroe CA, Dueck AC, Lee JJ, Nunez-Nateras R, et al. Androgen receptor-positive triple negative breast cancer: A unique breast cancer subtype. Ann Surg Oncol. 2014;21(2):361-7. https://doi.org/10.1245/ s10434-013-3260-7

PMid:24046116 